\title{
A Facile Route to Melaminophenyl Boronates using 2, 4-Diazido-6- Chloro-1, 3, 5-Triazine as an Electrophilic Reagent
}

\section{Claudius D'Silva}

Faculty of Science and Engineering, School of Chemistry \& Environmental Sciences, The Manchester Metropolitan University, Manchester, UK

E-mail: C.DSilva@ymail.com

Received: 16 November 2020; Revised: 15 January 2021; Accepted: 15 January 2021

Abstract: We have synthesised a novel class of melaminyl derivative, containing a phenyl boronate or boronate ester group. The synthetic methodology employed was designed to be facile involving the use of 2, 4-diazido-6-chloro-1, 3, 5-triazine as an electrophilic reagent for nucleophilic substitution of chlorine with a weakly reactive amine. The reagent was chosen with a view to improve the organic solubility of the product and aid isolation by allowing the reaction to be followed by fluorescence quenching (Tlc, $\mathrm{F}_{234}$ ) and IR (the presence of two $\mathrm{N}_{3}$ peaks).

Keywords: boronates, melarsoprol, diazidotriazine, BNCT, melaminophenyl boronates

\section{Introduction}

The 1, 3, 5 triazine skeleton and its derivatives are present in herbicides such as simazine, atrazine, the melaminyl dithiaarsane drug, melarsoprol (Figure 1), used for the treatment of late stage East African trypanosomiasis ${ }^{1,2}$ and in the treatment of cardiovascular, neuropsychiatric disorders, diabetes, cancer and as a diuretic agent. ${ }^{3,4}$ Melarsoprol alone or with all-trans-retinoic acid (ATRA) has shown promise in retarding the growth and anti-proliferative activity of MCF-7 human breast cancer cells, as well as the PC-3 and DU 145 human prostate cancer cells, both in vitro and in vivo.

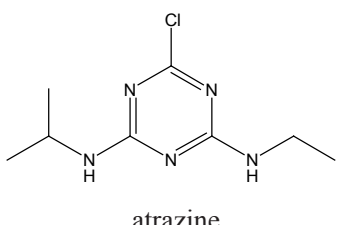

atrazine

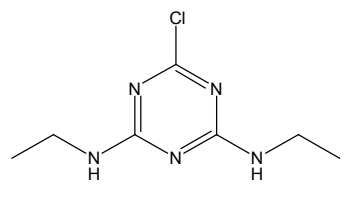

simazine

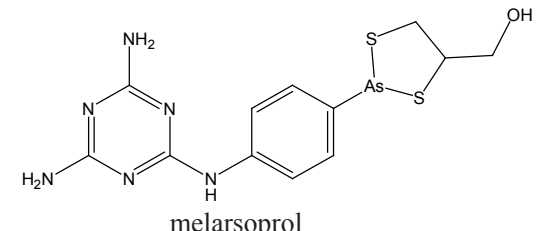

melarsoprol

Figure 1. The chemical structures of melaminyl molecules with biological activity

Boronic acid derivatives have been studied extensively as potential therapeutics. ${ }^{6-9}$ A number of boronate peptides, heterocyclic benzoxaboroles and diazaborines have been identified with biological activity against a variety of diseases.

Copyright (C2021 Claudius D’Silva

DOI: https://doi.org/10.37256/ocp.212021716

This is an open-access article distributed under a CC BY license

(Creative Commons Attribution 4.0 International License)

https://creativecommons.org/licenses/by/4.0/ 
Some have been used clinically or have entered human clinical trials for cancer and as antifungal, anti-inflammatory, antibacterial, antimalarial, antitrypanosomiasis agents as exemplified by PS-341, AN2690, AN2728, AN3365 $\left(\mathrm{GSK}^{\prime} 052\right),{ }^{10}$ diazaborine and AN5568 (SCYX-7158) ${ }^{11}$ (Figure 2). Some boron compounds, preferentially accumulate in certain types of cancers such as boronophenylalanine (BPA) (Figure 2) and have found use in boron neutron capture therapy (BNCT), a targeted radiotherapy for cancer cells. ${ }^{12,13}$ The therapy is based on the capture by the boron-10 nucleus of neutrons, when irradiated and its subsequent fission to yield an alpha particle $\left({ }^{4} \mathrm{He}\right)$ and recoiling lithium $\left({ }^{7} \mathrm{Li}\right)$ nuclei. Boron neutron capture therapy is primarily used for the treatment of difficult-to-treat tumours, particularly brain tumours, where surgery, chemotherapy, and radiotherapy prove ineffective or lead to the incapacity of the patient.<smiles>OB1Cc2cc(F)ccc21</smiles>

AN 2690<smiles>N#Cc1ccc(Oc2ccc3c(c2)COB3O)cc1</smiles>

AN 2728<smiles>CC(C)C[C@H](NC(=O)[C@H](Cc1ccccc1)NC(=O)c1cnccn1)B(O)O</smiles>

Velcade (bortezomib; PS-341)<smiles>NC[C@H]1OB(O)c2c(OCCCO)cccc21</smiles>

GSK'052<smiles>C=C(Nc1ccc2c(c1)B(O)OC2(C)C)c1ccc(F)cc1C(C)(C)C</smiles>

SCYX-7158<smiles>CCCS(=O)(=O)N1N=Cc2sc(C)cc2B1O</smiles>

Diazaborine

BPA

Figure 2. The chemical structures of boron-containing molecules with biological activity

Our interest in melaminyl derivatives is in the preparation of a bioisosteric analogue of melarsoprol (Figure 1) in which the arseno group is replaced by a boronate group that is topologically similar and share some of its physiochemical properties. The traditional synthetic route to this type of compound involves the reaction of 2 , 4-diamino-6-chloro-1, 3, 5-triazine with an amino substituted phenylboronate. However, the diamino groups on the triazine ring reduces the electrophilic character of the chlorine to nucleophilic substitution, requiring hard conditions (reflux EtOH $/ \mathrm{H}_{2} \mathrm{O}$ ) to achieve product formation even with reactive amines which creates problems, such as the loss of protecting groups ${ }^{14}$ and with sterically hindered amines, like 1-adamantanamine, ${ }^{15}$ heating at $285^{\circ} \mathrm{C}$ in sulfolane. The use of solvent free microwave conditions on silica-gel at $800 \mathrm{~W}$ offer a solution, for sterically hindered amines. ${ }^{16}$ However, when the amine is poorly nucleophilic, due to an electron withdrawing boronate substituent, have a labile protecting group, then substitution and isolation becomes problematic. This paper describes the use of 2, 4-diazido-6-chloro-1, 3, 5-triazine as a new facile reagent for the preparation of melaminophenyl boronates, that have not been previously prepared, as bioisosteric analogues of melarsoprol (Figure 3).

\section{Experimental section}

All commercially available reagents were purchased from Sigma-Aldrich (UK), or Alfa Aesar (UK) and used without purification. Melting points were determined on an Electrothermal apparatus and are uncorrected unless specified otherwise. Preparative thin-layer chromatography (PTLC) was performed on silica gel $60 \mathrm{~F}_{234}$ plates purchased from Merck. ${ }^{1} \mathrm{H}$ and ${ }^{13} \mathrm{C}$ Nuclear Magnetic Resonance (NMR) spectra were obtained in the designated solvent and frequency on a Japan Electron Optics Laboratory (JEOL) 270 MHz Fourier transform NMR (FTNMR) spectrometer using trimethylsilane as an internal standard. Infrared spectra were recorded with a Thermo Nicolet 370 Fourier Transform Infrared spectrometer (FTIR). Mass spectrometry was undertaken as a service at the Environmental Physical 
Research Council (EPSRC) mass spectrometry facility at Swansea (UK). The preparation, storage and reaction of azido compounds was carried out in reaction vessels protected with aluminium foil. Care should be taken in the handling (light and heat sensitivity) and storage of large quantities of 2, 4-diazido-6-chloro-1, 3, 5-triazine (2) due to the explosive properties of related compounds reported in the literature. ${ }^{17,18}$ We note that dilute solution of $\mathbf{2}$ left to evaporate in thin glass vials in the dark on many occasions were found shattered.

\subsection{2, 4-Diazido-6-chloro-1, 3, 5-triazine (2)}

To an ice cold stirred solution of cyanuric chloride $(1)(2 \mathrm{~g} ; 0.011 \mathrm{M})$ suspended in acetone $\left(80 \mathrm{~cm}^{3}\right)$ was added a solution of sodium azide $(1.55 \mathrm{~g} ; 0.024 \mathrm{M})$ in water $\left(10 \mathrm{~cm}^{3}\right)$. After $1 \mathrm{~h}$, a precipitate was formed, which was filtered, washed with water and dried. The filtrate was then evaporated under vacuum to a small volume, water added and a further quantity of precipitate filtered, washed with water, and suction dried under vacuum over $\mathrm{P}_{2} \mathrm{O}_{5}$. The combined colourless precipitates, totalled $1.2 \mathrm{~g} ; 55.4 \%$ and were determined homogenous by TLC and used, without further purification (cyanuric azide and polyazido nitrogen rich molecules ${ }^{18}$ can be explosive by nature and structural confirmation of such compounds require the use of crystallography ${ }^{17}$ due to thermal decomposition and re-arrangement using mass spectral techniques, so was used as isolated). ${ }^{19}$ Infrared Radiation (IR) (vmax) (nujol mull): 2350, $2159 \mathrm{~cm}^{-1}$ $(\mathrm{N})^{20}$.

\subsection{4, 6-Diazido-N-(4-(4, 4, 5, 5-tetramethyl-1, 3, 2-dioxaborolan-2-yl) phenyl)-1, 3, 5-triazine-2-amine (4)}

A mixture of 4-aminophenylboronic acid pinacol ester (3) (0.3 g; $0.0014 \mathrm{M})$, 2, 4-diazido-6-chloro-1, 3, 5-triazine (2) $(0.21 \mathrm{~g} ; 0.0014 \mathrm{M})$, DMAP $(0.008 \mathrm{~g} ; 0.065 \mathrm{mM})$ was dissolved in a $1: 1$ mixture of THF \& DIPEA $\left(5 \mathrm{~cm}^{3}\right)$ and the solution left stirring at room temperature (RT) for $20 \mathrm{~h}$. Chloroform was then added to the reaction mixture and the solution washed with $\mathrm{HCl}(1 \mathrm{M})$, water, brine, dried $\left(\mathrm{MgSO}_{4}\right)$ and evaporated under vacuum to give an oil. Tituration of the oil $(2 \times)$ with pet-ether $(40-60)$ and decantation caused solidification of the product to give a colourless solid $(0.2 \mathrm{~g}$; 38.14\%). Mp; $138-140^{\circ} \mathrm{C} .{ }^{1} \mathrm{H}$ NMR $\left(\mathrm{CDCl}_{3}\right) \delta 1.34\left(\mathrm{~s} ; 4 \times \mathrm{CH}_{3}\right), 7.6(\mathrm{~d} ; 2 \times \mathrm{ArH}), 7.64(\mathrm{bs} ; \mathrm{NH}), 7.8(\mathrm{~d} ; 2 \times \mathrm{ArH}) . \mathrm{C}^{13}$ $\left(\mathrm{CDCl}_{3}\right) \delta$ 25.0, 84.0, 119.5, 135.6, 141.5, 154.20. IR (vmax) (nujol mull): $3318(\mathrm{NH}) ; 2170,2135\left(\mathrm{~N}_{3}\right), 1356(\mathrm{~B}-\mathrm{O})$. HRMS: (ESI) $\mathrm{m} / \mathrm{z}$ Calc for $\mathrm{C}_{15} \mathrm{H}_{16} \mathrm{O}_{2} \mathrm{~N}_{10} \mathrm{~B}[\mathrm{M}-\mathrm{H}] 379.1556$ Found 379.1547.

\section{$2.3 \mathrm{~N}^{2}$-(4-(4, 4, 5, 5-Tetramethyl-1, 3, 2-dioxaborolan-2-yl) phenyl)-1, 3, 5-triazine-2, 4.6-triamine (5)}

4, 6-Diazido-N-(4-(4, 4, 5, 5-tetramethyl-1, 3, 2-dioxaborolan-2-yl) phenyl)-1, 3, 5-triazine-2-amine (4) (0.19 g; $0.0005 \mathrm{M})$ dissolved in EtOH $\left(5 \mathrm{~cm}^{3}\right)$ containing $\mathrm{Pd} / \mathrm{C}(10 \%)(0.015 \mathrm{~g})$ was hydrogenated for $20 \mathrm{~h}$. The solution was filtered through celite, washed with EtOH and EtOAc and evaporated under vacuum to give an oil which was dissolved in a small amount of acetone and precipitated with hexane as colourless crystals $(0.13 \mathrm{~g} ; 78.0 \%) . \mathrm{Mp} ; 244-248^{\circ} \mathrm{C}$ (decomp). ${ }^{1} \mathrm{HNMR}\left(\mathrm{D}_{6} \mathrm{MSO}\right) \delta 1.31\left(\mathrm{~s} ; 4 \times \mathrm{CH}_{3}\right), 3.87\left(\mathrm{bs} ; \mathrm{H}_{2} \mathrm{O}\right), 7.68(\mathrm{~d} ; 2 \times \mathrm{ArH}), 7.77(\mathrm{~d} ; 2 \times \mathrm{ArH}) . \mathrm{C}^{13}\left(\mathrm{D}_{6} \mathrm{MSO}\right) \delta$ 25.3, 84.02, 120.18, 135.33, 142.79, 147.19, 160.31, 162.13. IR (vmax) (nujol mull); 3329, 3164 (NH); 1361 (B-O); HRMS (ESI) $\mathrm{m} / \mathrm{z}$ Calc for $\mathrm{C}_{15} \mathrm{H}_{23} \mathrm{O}_{2} \mathrm{~N}_{6} \mathrm{~B}[\mathrm{M}+\mathrm{H}] 329.1892$ Found 329.1896.

\subsection{4-(4, 6-Diamino-1, 3, 5-triazin-2-ylamino) phenylboronic acid (6)}

$\mathrm{N}^{2}$-(4-(4, 4, 5, 5-tetramethyl-1, 3, 2-dioxaborolan-2-yl) phenyl)-1, 3, 5-triazine-2, 4.6-triamine (5) (0.050 g ; $0.00015 \mathrm{M})$ was dissolved in $\mathrm{MeOH}\left(3 \mathrm{~cm}^{3}\right)$ and TEA.3HF $(0.12 \mathrm{~g} ; 0.00074 \mathrm{M})$ added drop wise to the stirred solution. After $24 \mathrm{~h}$ at room temperature, water was added to the solution and it was evaporated to dryness. The residue was suspended in water and extracted with EtOAc and the aqueous suspension evaporated to dryness. The residue was suspended in a small amount of water and filtered to give the product $(0.019 \mathrm{~g} ; 51.5 \%)$ as colourless crystals on drying over $\mathrm{P}_{2} \mathrm{O}_{5}$. Mp; $178-182^{\circ} \mathrm{C} .{ }^{1} \mathrm{H}$ NMR $\left(\mathrm{D}_{6} \mathrm{MSO}\right) \delta 7.3\left(\mathrm{~d} ; 2 \times \mathrm{NH}_{2}\right), 7.7(\mathrm{~m} ; 4 \times \mathrm{ArH}), 9.73(\mathrm{~s}, \mathrm{NH}), 11.2(\mathrm{bs}, \mathrm{BOH}) . \mathrm{C}^{13}$ $\left(\mathrm{D}_{6} \mathrm{MSO}\right) \delta 118.25,121.44,131.60,150.87,158.89,176.24$. IR (KBr), 3620, $3439(\mathrm{~B}-\mathrm{OH}), 3368,3272,3183(\mathrm{~N}-\mathrm{H})$; 1326 (B-O). HRMS: (ESI) m/z Calc for $\mathrm{C}_{9} \mathrm{H}_{12} \mathrm{~N}_{6} \mathrm{O}_{2} \mathrm{~B}$ [M $+\mathrm{H}$ ] 247.1109 Found 247.1113. HRMS (ESI) $\mathrm{m} / \mathrm{z}$ Calc for $\mathrm{C}_{9} \mathrm{H}_{12} \mathrm{~N}_{6} \mathrm{~B} \mathrm{O} \mathrm{O}_{2}[\mathrm{M}+\mathrm{Na}] 269.0940$ Found 269.0932. 


\subsection{3-(4, 6-Diazido-1, 3, 5-triazin-2-ylamino) phenylboronic acid (8)}

A mixture of 3-aminophenylboronic acid (7) (1.0 g; 0.0073 M), 2, 4-diazido-6-chloro-1, 3, 5-triazine (2) (1.0 g; $0.0064 \mathrm{M})$, DMAP $(0.01 \mathrm{~g} ; 0.082 \mathrm{mM})$ was dissolved in a $1: 1$ mixture of THF \& DIPEA $\left(20 \mathrm{~cm}^{3}\right)$ and the solution left stirring at RT for $20 \mathrm{~h}$. The solution was partially evaporated to remove THF and extracted with pet ether $\left(60-80^{\circ}\right)$, then acidified with $\mathrm{HCl}(1 \mathrm{M})$ and extracted with EtOAc with a small amount of $\mathrm{MeOH}$ to solubilise undissolved material. Then washed with water, brine, dried $\left(\mathrm{MgSO}_{4}\right)$ and evaporated under vacuum to give a colourless solid $(0.54 \mathrm{~g} ; 28.1 \%)$. $\mathrm{Mp} ;>360^{\circ} \mathrm{C}$ (decomp). ${ }^{1} \mathrm{H}$ NMR $\left(\mathrm{D}_{6} \mathrm{MSO}\right) \delta 3.8\left(\mathrm{~s}, \mathrm{~B}(\mathrm{OH})_{2}, \mathrm{NH}, 2 \times \mathrm{NH}_{2}, \mathrm{H}_{2} \mathrm{O}\right), 7.31$ (t, Ar-H), 7.55 (d, Ar-H), 7.66 (t, t, Ar-H), 7.99 (s, Ar-H). $\mathrm{C}^{13} 123.85,127.83,128.13,130.50,137.51,165.41,170.06,170.92$. IR (vmax) (KBr) 2174,2135 $\left(\mathrm{N}_{3}\right), 1341$ (B-O). HRMS (ESI) Calc for $\mathrm{C}_{9} \mathrm{H}_{7} \mathrm{~N}_{10} \mathrm{O}_{2} \mathrm{~B}[\mathrm{M}+\mathrm{H}] 299.0924$ Found 299.0924.

\subsection{3-(4, 6-Diamino-1, 3, 5-triazin-2-ylamino) phenylboronic acid (9)}

3-(4, 6-Diazido-1, 3, 5-triazin-2-ylamino) phenylboronic acid (8) (0.3 g; $0001 \mathrm{M})$ dissolved in EtOH $\left(5 \mathrm{~cm}^{3}\right)$ containing $\mathrm{Pd} / \mathrm{C}(10 \%)$ (0.04 g) was hydrogenated for $20 \mathrm{~h}$. The solution was diluted with hot ethanol and filtered through celite, washed with EtOH and evaporated under vacuum to give an oil which solidified to give cream coloured crystals. The crystals were titurated in diethyl ether, filtered and obtained as cream coloured crystals $(0.19 \mathrm{~g} ; 76.2 \%)$. $\mathrm{Mp} ; 220^{\circ} \mathrm{C}$ (decomp). ${ }^{1} \mathrm{H}$ NMR $\left(\mathrm{D}_{6} \mathrm{MSO}\right) ; \delta 3.7$ (bs, $\left.\mathrm{B}(\mathrm{OH})_{2}, \mathrm{NH}, 2 \times \mathrm{NH}_{2}, \mathrm{H}_{2} \mathrm{O}\right) ; 7.3$ (t, Ar-H), 7.56 (d, Ar-H), 7.72 (t, Ar-H). $\mathrm{C}^{13}$ (D $\left.\mathrm{D}_{6} \mathrm{MSO}\right) ; \delta 125.07,128.40,128.59,130.86,137.20,141.73,167.0$. IR (vmax) (nujol mull); 3343 (B-OH), $3188(\mathrm{NH}) ; 1338$ (B-O); HRMS (ESI) Calc for $\mathrm{C}_{9} \mathrm{H}_{11} \mathrm{~N}_{6} \mathrm{O}_{2} \mathrm{~B}[\mathrm{M}+\mathrm{H}] 247.1109$ Found 247.1112.

\section{Results and discussion}

As shown in Figure 3, commercially available 4-aminophenylboronic acid pinacol ester $\mathbf{3}$ was used as the starting material as well as 3-aminophenylboronic acid, 7. 3-Aminophenyl boronic acid was investigated to ascertain if the technique could be used without boronate group protection, in regard to product isolation and purification.

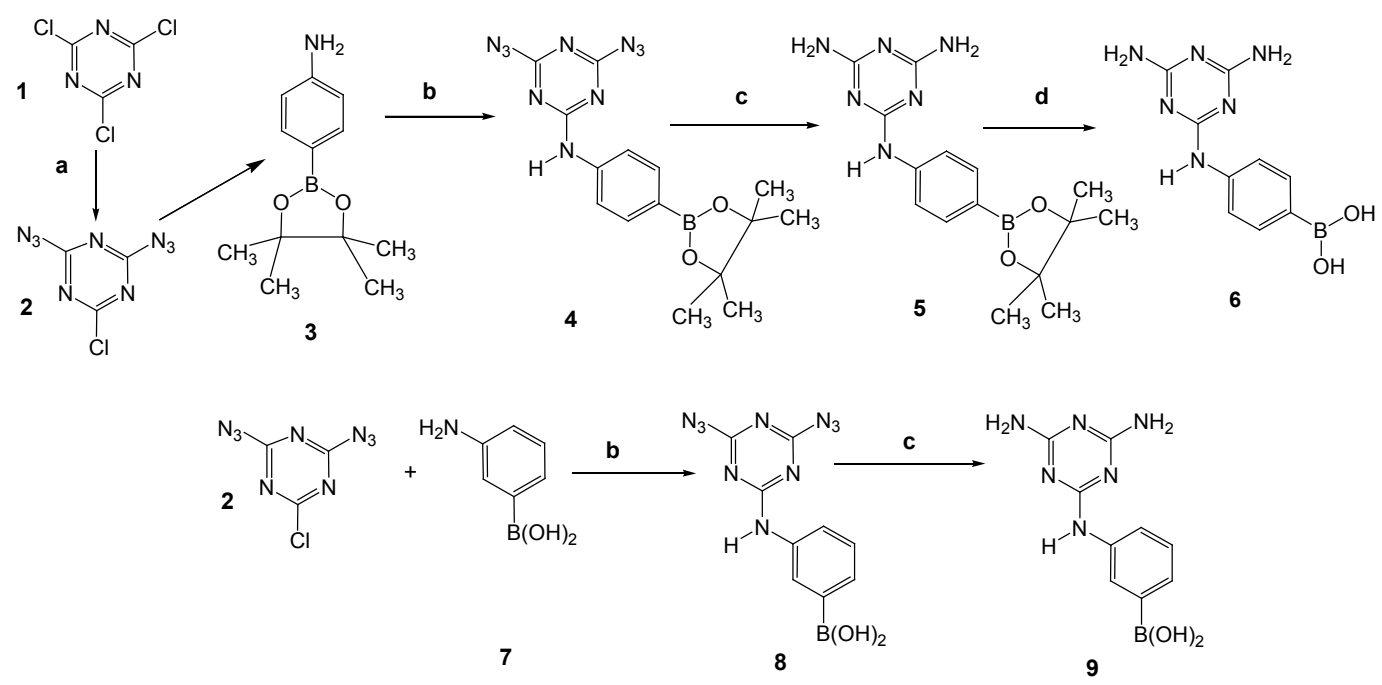

Figure 3. Reagents and conditions: (a) Sodium azide, $\left(\mathrm{CH}_{3}\right)_{2} \mathrm{CO} / \mathrm{H}_{2} \mathrm{O}, 0^{\circ} \mathrm{C}, 1 \mathrm{~h}$; (b) THF/DIPEA, DMAP, RT, 20 h; (c) Pd/C/EtOH, 20 h, RT; (d)TEA.3HF/MeOH, 24 h, RT

Our synthetic strategy was to identify a triazine reagent with enhanced electrophilic character, where the diamino groups were masked, as in, 2, 4-diazido-6-chloro-1, 3, 5-triazine, 2. The role of the diazo groups was to improve the electrophilic characteristics of the chlorine on the triazine ring, to nucleophilic substitution whilst enhancing the 
compounds solubility in organic solvents. The conjugation of the diazo groups with the triazine ring, also enhanced the UV fluorescence quenching properties of the reagent, allowing the reaction to be followed by Tlc, $\mathrm{F}_{254}$ and its incorporation into the product by IR, two $\mathrm{N}_{3}$ peaks $\left(2364 \& 2132 \mathrm{~cm}^{-1}\right.$ for HTPB-DT). ${ }^{19}$ Compound 2 was prepared as described in the literature ${ }^{19}$ by reaction of cyanuric chloride, 1 with $\mathrm{NaN}_{3}(2$ mols $)$ at $0^{\circ} \mathrm{C}$ in aqueous acetone and isolated in good yield. The presence of two diazido group in 2 at $2350 \& 2159 \mathrm{~cm}^{-1}$, by $\mathrm{IR}^{20}$ confirmed the substitution of the two chlorines in $\mathbf{1}$. Reaction of the triazine derivative $\mathbf{2}$ with $\mathbf{3}$, under mild conditions in THF/DIPEA at room temperature gave the desired protected product, compound $\mathbf{4}$ without the need for extreme conditions confirming the facile nature of the reaction. IR confirmed the incorporation of the triazine group into the product the NH group at 3318 $\mathrm{cm}^{-1}$, the two $\mathrm{N}_{3}$ peaks, at $2170 \& 2135 \mathrm{~cm}^{-120}$ and a peak for the boronate group ${ }^{21-24}$ at 1356 (B-O). The structure of the compound was confirmed by ${ }^{1} \mathrm{H}$ NMR, the pinacol ester at $\delta 1.31$ and the aromatic peaks at $\delta 7.68-7.77$, the $\mathrm{C}^{13} \mathrm{NMR}$ and HRMS were in agreement with the molecular formula. Deprotection of $\mathbf{4}$ to $\mathbf{6}$ was undertaken via a two-step process that involved first the reduction of the diazido group to the diamino group using hydrogenation, with $\mathrm{Pd} / \mathrm{C}(10 \%)$ to give 5 in good yield. The loss of the two $\mathrm{N}_{3}$ peaks in the IR at $2170 \& 2135 \mathrm{~cm}^{-1}$ and the appearance of two NH peaks at 3329 and $3164 \mathrm{~cm}^{-1}$ in 5 confirmed the reduction of $\mathrm{N}_{3}$ to $\mathrm{NH}_{2}$, and a peak a $1361(\mathrm{~B}-\mathrm{O})$ for the boronate group. The ${ }^{1} \mathrm{H}$ NMR confirmed the presence of the pinacol ester at $\delta 1.31$ and aromatic group at $\delta$ 7.68-7.7. The $\mathrm{C}^{13} \mathrm{NMR}$ and HRMS were in agreement with the molecular formula. Finally, the removal of the boronate ester group $\mathbf{5}$ was achieved by transesterification, using TEA.3HF in $\mathrm{MeOH}^{25}$ to give the desired product 6 , in $51.5 \%$ yield. Removal of the pinacol ester group, resulted in the appearance of two new peaks in the IR, due to the B-OH group at 3620 and $3439 \mathrm{~cm}^{-1}$. The loss of the peak at $\delta 1.31$ in the ${ }^{1} \mathrm{H}$ NMR, confirmed removal of the pinacol ester and $\delta 7.7$ the presence of the aromatic group. The $\mathrm{C}^{13} \mathrm{NMR}$, and HRMS were in agreement with the molecular formula.

Given the encouraging results in the preparation of compound 4 the reaction of reagent 2 was repeated with 3 -aminophenylboronic acid, 7, to test the generality of the reaction. Compound 8 was isolated in moderate yield and the presence of the diazo groups was confirmed in the product, by two $\mathrm{N}_{3}$ peaks in the IR at 2135 and $2174 \mathrm{~cm}^{-1} .20$ The compound structure was consistent with the ${ }^{1} \mathrm{H}$ and $\mathrm{C}^{13} \mathrm{NMR}$, and HRMS were in agreement with the molecular formula. Conversion of the diazido groups of $\mathbf{8}$ to the diamino $\mathbf{9}$ was undertaken as in $\mathbf{5}$ by hydrogenation with $\mathrm{Pd} / \mathrm{C}$ $(10 \%)$ to give the product in good yield. The IR confirmed the loss of the azido group and the compound structure was consistent with the ${ }^{1} \mathrm{H}$ and $\mathrm{C}^{13} \mathrm{NMR}$, and HRMS were in agreement with the molecular formula.

\section{Conclusion}

In summary, we have synthesised a novel class of triazine compound containing a boronate group. The design concept involved an isosteric replacement of the arsenical group of melarsoprol by a topologically similar boronate group that is capable of adduct formation with oxygen and thiol ligands. The availability of a facile method, to introduce the melaminophenyl group has importance to developing new triazine molecules with labile functional groups under mild conditions (RT).

\section{Declaration of conflicting interests}

The author declares no potential conflicts of interest with respect to the research, authorship and/or publication of this article.

\section{Acknowledgments}

The authors thank EPSRC for support under Grant GR/F 20937. Thanks is expressed to Prof. D.E. Games \& B. Stein of the EPSRC Mass Spectrometry service centre, Swansea (UK) for MS \& ESIMS measurements. 


\section{References}

[1] Brun, R.; Blum, J.; Chappuis, F.; Burri, C. Human African trypanosomiasis. Lancet 2010, 375, 148-59.

[2] D'Silva, C. Human African trypanosomiasis: future prospects for chemotherapy. Drug. Future. 2007, 32, 149-160.

[3] Liu, B.; Sun, T.; Zhou, Z.; Dui, L. A systematic review on antitumour agents with 1, 3, 5-triazines. Med. Chem. 2015, 5, 131-148.

[4] Cascioferro, S.; Parrino, B.; Spano, V.; Carbone, A.; Montalbarro, A.; Barraja, P.; Diana, P.; Cirrincione, G. Eur. J. Med. Chem. 2017, 142, 523-549.

[5] Koshiuka, K.; Elstner, E.; Williamson, E.; Said, J. W.; Tada, Y.; Koeffler, H. P. Novel Therapeutic approach: Organic arsenical (melarsoprol) alone or with all-trans-retinoic acid markedly inhibit growth of human breast and prostate cancer cells in vitro and in vivo. B. J. Cancer. 2000, 82, 452-458.

[6] Touchet, S.; Carreaux, F.; Carboni, B.; Bouillon, A.; Boucher, J-L. Aminoboronic acid and esters: from synthetic challenges to the discovery of unique classes of enzyme inhibitors. Chem. Soc. Rev. 2001, 40, 3895-3914.

[7] Barker, S.; Tomsho, J. W.; Benkovic, S. J. Boron-containing inhibitors of Synthases. Chem. Soc. Rev. 2001, 40, 4279-4285.

[8] Sekhon, B. S. Metalloid compounds as drugs. RPS. 2013, 8, 145-158.

[9] Ciapetti, P.; Giethlen, B. Molecular variations based on isosteric replacements. In Practice of Medicinal Chemistry; Wermuth, C. G., Eds., $3^{\text {rd }}$ ed.; Academic Press: USA, 2008; pp 331-333.

[10] Jacobs, R. T.; Plattnerb, J. J.; Keenan, M. Boron-based drugs as antiprotozoals. Curr. Opin. Infect. Dis. 2011, 24, 586592.

[11] Jacobs, R.T.; Nare, B.; Wring, S. A.; Orr, M. D.; Chen, D.; Sligar, J. M.; Jenks, M. X.; Noe, R. A.; Bowling, T. S.; Mercer, L. T.; Rewerts, C.; Gaukel, E.; Owens, J.; Parham, R.; Randolph, R.; Beaudet, B.; Bacchi, C. J.; Yarlett, N.; Plattner, J. J.; Freund, Y.; Ding, C.; Akama, T.; Zhang, Y. K.; Brun, R.; Kaiser, M.; Scandale, I.; Don, R. SCYX7158, an Orally-Active Benzoxaborole for the Treatment of Stage 2 Human African Trypanosomiasis. PLoS. Neg. Trop. Dis. 2011, 5, e1151. doi:10.1371/journal, pntd.0001151.

[12] Dymova, M. A.; Taskaev, S. Y.; Richter, V. A.; Kuligina, E. V. Boron neutron capture therapy: Current status and future perspectives. Cancer Commun. 2020, 40, 406-421.

[13] Nedunchezhian K, Aswath N, Thiruppathy M, Thirugnanamurthy S. Boron neutron capture therapy-A literature review. J. Clin. and Diagnostic Res. 2016, 10, 1-4

[14] Klenke, B.; Stewart, M.; Barrett, M. P.; Brun, R.; Gilbert, I. H. Synthesis and biological evaluation of s-triazine substituted polyamines as potential new anti-trypanosomal drugs. J. Med. Chem. 2001, 44, 3440-3452.

[15] Hedayatullah, M.; Lion, C. L.; Slimane, A. B.; Da Conceiçao, L.; Nachawati, I. Synthesis of reactive s-triazines bearing a cage system derived from adamantine as precursors of hexamethymelamine analogues. Heterocycles 1999, 51, 1891-1896.

[16] Kurteva, V. B.; Afonso, C. A. M. Solvent-free synthesis of melamines under microwave irradiation. Green. Chem. 2004, 6, 183-187.

[17] Keßenich, E.; Klapötke, T. M.; Knizek, J.; Nöth, H.; Schulz, A. Characterization, Crystal Structure of 2, 4-Bis (triphenylphosphanimino) tetrazolo [5, 1-a]-[1, 3, 5] triazine,and Improved Crystal Structure of 2, 4, 6-Triazido-1, 3, 5-triazine. Eur. J. Inorg. Chem. 1998, 2013-2016.

[18] Huynh, My-HV.; Hiskey, M. A.; Chavez, D. E.; Naud, D. L.; Gilardi, R. D. Synthesis, characterization, and energetic properties of diazido heteroaromatic high-nitrogen C-N compound. J. Am. Chem. Soc. 2005, 127, $12537-$ 1254.

[19] Enwin, N.; Ludwig, E. Pesticidal triazinyl azides. U.S. Patent 3415827A. 1968. https://patents.google.com/patent/ US3415827.

[20] Sankar, R. M.; Roy, T. K.; Jan, T. Functionalization of terminal carbon atoms of hydroxyl terminated polybutadiene by polyazido nitrogen rich molecules. Bull. Mater. Sci. 2011, 34, 745-754.

[21] Werner, R. L.; O’Brien, K. G. The infra-red spectra of the borate esters. Aust. J. Chem. 1955, 8, 355-360.

[22] Bethell, D. E.; Sheppard, N. The infra-red spectrum and structure of boric acid. Trans. Faraday. Soc. 1955, 51, 9-15.

[23] Szeleczky, Z.; Soti, M.; Horvath, Gy.; Albrecht, K. 7ß-hydroxycardenolide glycosides. Steroids. 1981, $38,11-27$.

[24] Tuldahar, S. M.; D’Silva, C. Synthesis of 2-Borono-1, 3-xylyl Macrocycles. Tetrahedron Lett. 1992, 33, $263-268$.

[25] Brown, H.C.; Rangaishenvi, M. V. L. I. Convenient procedures for the recovery of pinanediol in asymmetric synthesis via one-carbon homologation of boronic esters. J. Organomet. Chem. 1988, 358, 15-30. 